\title{
Cestode parasitism as a regulator of early life-history survival in an estuarine population of rainbow smelt Osmerus mordax
}

\author{
Jean-François Bourque ${ }^{1}$, Julian J. Dodson ${ }^{1, *}$, Daniel A. J. Ryan ${ }^{2}$, \\ David J. Marcogliese ${ }^{3}$ \\ ${ }^{1}$ Département de biologie, Université Laval, Pavillon Vachon, Quebec, Quebec G1K 7P4, Canada \\ ${ }^{2}$ Department of Mathematics and Statistics, University of Prince Edward Island, 550 University Avenue, Charlottetown, \\ Prince Edward Island C1A 4P3, Canada \\ ${ }^{3}$ St. Lawrence Centre, Environment Canada, 105 McGill, 7th floor, Montreal, Quebec H2Y 2E7, Canada
}

\begin{abstract}
In the St. Lawrence middle estuary, the larvae and juveniles of rainbow smelt Osmerus mordax are infected with intestinal parasites (the cestode Proteocephalus tetrastomus). Such parasitism is suspected to impair growth rate, which may in turn influence the ability of smelt to migrate vertically and to be retained in the estuarine turbidity maximum (ETM), the nursery area of this population. We hypothesised that parasitism contributes to size-selective mortality by altering patterns of vertical migration, thus contributing to transport losses from the nursery area. Parasitism was found to affect growth rate, as determined by otolith microstructure analysis, and to contribute to mortality. Larvae which survived the parasitic infection were found to be, on average, larger than the uninfected survivors at some point in their early life history prior to infection. Significant sizeselective mortality was observed among infected larvae relative to uninfected larvae. There was, however, no significant difference in the vertical distribution of parasitised versus non-parasitised larvae, indicating that size-selective mortality was not due to transport losses from the nursery area. Rather, starvation or predation was most likely responsible for observed mortality patterns. We illustrate that variability in the incidence of parasitic infection among years may form the basis for variability in recruitment and the abundance of the adult smelt population.
\end{abstract}

KEY WORDS: Parasite $\cdot$ Recruitment $\cdot$ Smelt $\cdot$ Otolith $\cdot$ Larvae $\cdot$ Size-selective mortality $\cdot$ Body size Cestodes $\cdot$ Estuarine turbidity maximum

\section{INTRODUCTION}

The presence of parasites in fish larvae has been noted in many independent studies involving different fish species (Rosenthal 1967, Baturo 1978, Courtois \& Dodson 1986, Dauvin \& Dodson 1990, Heath \& Nicoll 1991, Balbuena et al. 2000, Sirois \& Dodson 2000a,b, Karlsbakk et al. 2001). The effect of parasitism is suspected to be strongest during the fragile early lifehistory stages, during which $>99 \%$ of the mortality of a fish cohort may occur, with profound effects on the abundance of adult populations (Cushing 1975). Star- vation, transport losses due to advection or dispersion out of nursery areas and predation have been identified as the major causes of early life-history mortality in fishes (Hjort 1914, Cushing 1975, Lasker 1978, Sinclair 1988, Bailey \& Houde 1989). Parasitism can potentially exacerbate all 3 mechanisms (Sindermann 1986, Barber et al. 2000) and may thus influence recruitment to the adult population.

The most common impact of a parasite is an energetic one, because parasites habitually exploit the nutritional resources of their host. Heath \& Nicoll (1991) and Sirois \& Dodson (2000a) demonstrated, 
respectively, that parasitised herring and smelt larvae had significantly less food in their gut than nonparasitised larvae. Three reasons may explain this: the parasite may consume a certain proportion of the ingested prey (Heath \& Nicoll 1991), the parasite may affect the host's ability to capture prey (Barber et al. 2000) and the available space for food in the gut of the host may be diminished by the presence of the parasite (Sirois \& Dodson 2000a). This loss of energy may affect survival by increasing the probability of starvation, reducing the growth rate and, as a possible consequence, increasing the period of vulnerability to predation.

Parasitism may alter the longitudinal and vertical distribution of fish and contribute to transport losses from areas that offer optimal conditions for survival. Parasitised fish have been found significantly higher in the water column than uninfected conspecifics (Arme \& Owen 1967, Lester 1971, Bean \& Winfield 1992). LoBue \& Bell (1993) proposed that the infected fish might be more buoyant than uninfected ones, impairing their ability to dive. The presence of parasites in the environment may also alter the distribution of fish hosts if a lower level of infection can be achieved by occupying a particular type of habitat (Poulin \& FitzGerald 1989). Given that parasitism is known to affect aspects of host physiology (e.g. atrophy of the musculature, pathology of the nervous system), reduced swimming performance may also be an effect of parasitic infections (Baldwin et al. 1967, Smith \& Margolis 1970, Holmes \& Zohar 1990, Coleman 1993, Barber et al. 2000). Such effects may increase the probability that fish larvae and juveniles will be transported away from nursery areas by advection or dispersal.

An increase in the vulnerability to predation may also be a consequence of parasitic infections. As stated earlier, food deprivation reduces growth of the host, and small size generally increases susceptibility to predation (Miller et al. 1988). Impairment of swimming ability may also affect the host's ability to escape predators. In addition, host anti-predator behaviour may be affected, leading to a greater exposure of the fish to predation (Milinski 1985, Godin \& Sproul 1988).

In the St. Lawrence middle estuary, larvae of the north shore population of rainbow smelt Osmerus mordax are retained in the deep channels of the estuarine transition zone (Laprise \& Dodson 1989, Lecomte \& Dodson 2004). This zone is formed by the mixing of salt and freshwater and is characterised by high turbidity (forming an estuarine turbidity maximum, ETM), sharp gradients in salinity and temperature, and high concentrations of zooplankton that are exploited as food by larval and juvenile fishes (Vincent \& Dodson 1999, Winkler et al. 2003). Larval smelt migrate vertically to promote retention in this nursery area, moving actively to the bottom layer during the ebbing tide and to the surface during the flood tide (Laprise \& Dodson 1989). Net downstream displacement is thus minimised. Any factor that increases the probability of being transported out of the ETM will lead to greater mortality, as the conditions downstream of this region are sub-optimal for larval survival (Sirois \& Dodson 2000b).

Several authors have mentioned the presence of a cestode parasite in the gut cavity of St. Lawrence rainbow smelt larvae (Courtois \& Dodson 1986, Dauvin \& Dodson 1990, Sirois \& Dodson 2000a,b). A morphological evaluation and genetic analysis of the parasite revealed its conspecificity with Proteocephalus tetrastomus, a species-specific parasite of smelt (Osmeridae) previously known only from northern Europe, Russia and Japan (Scholz et al. 2004). This parasite is suspected of contributing to transport losses of the St. Lawrence smelt population by reducing growth and, hence, impairing vertical migration (Sirois \& Dodson 2000b). Such transport losses may be correlated with a significant size-selective mortality, whereby more slowly growing larvae show the greatest mortality rates (Sirois \& Dodson 2000a). We thus suspected differences to exist in the vertical distribution of infected and uninfected smelt larvae.

The major objective of the present study was to determine if parasitism influences survival of the early life-history stages of smelt. We first quantified the dynamics of the Proteocephalus tetrastomus infection and its impact on growth and size-selective mortality of larvae. We also tested the hypothesis that size-selective mortality was due to impaired vertical migration by evaluating the prediction that there would be a significant difference in the vertical distribution of infected and uninfected larvae.

\section{MATERIALS AND METHODS}

Parasitic infection and effect on growth. Study area and sampling: The ETM is located in the upstream part of the St. Lawrence middle estuary between Île d'Orléans and Île aux Coudres (Fig. 1). It encompasses a salinity range from 0.2 to $10 \mathrm{psu}$ and is characterised by a high rate of sediment resuspension (Kranck 1979). The region is hydrodynamically very energetic, with current speeds attaining $250 \mathrm{~cm} \mathrm{~s}^{-1}$. Circulation is controlled by 4 to $6 \mathrm{~m}$ semi-diurnal tides (D'Anglejan \& Smith 1973).

We sampled a station located in the middle channel of the ETM (Fig. 1) for 8 consecutive wk in the summer of 2001 (11 June to 8 August), to obtain Osmerus mordax larvae before and after the appearance of the parasite (preliminary analyses indicated that Proteocephalus tetrastomus was first found in the guts of 
smelt larvae at the end of June). Smelt spawn in mid-April in the fluvial region of the estuary, and larvae are first found in mid-May in the ETM. Due to bad weather, larvae from Week 6 of sampling could not be obtained. For each sampling, the procedure consisted of 15 min stepoblique tows from the bottom to the surface using a $500 \mu \mathrm{m}$ mesh, $1 \mathrm{~m}$ plankton net. All samples were preserved in $95 \%$ ethanol. For each sample, 25 to 100 larvae were randomly selected, and their lengths and widths were measured using a camera connected to an image analysis system (Sigma Scan Pro). Each larva was dissected under a microscope, and parasites observed in the digestive tract were counted and measured (length, width, height) using an ocular micrometer.

Infection dynamics and parasitism index: To describe the infection dynamics of the smelt larvae, we calculated the prevalence (percentage of fish infected), the mean abundance (average number of parasites in infected and uninfected

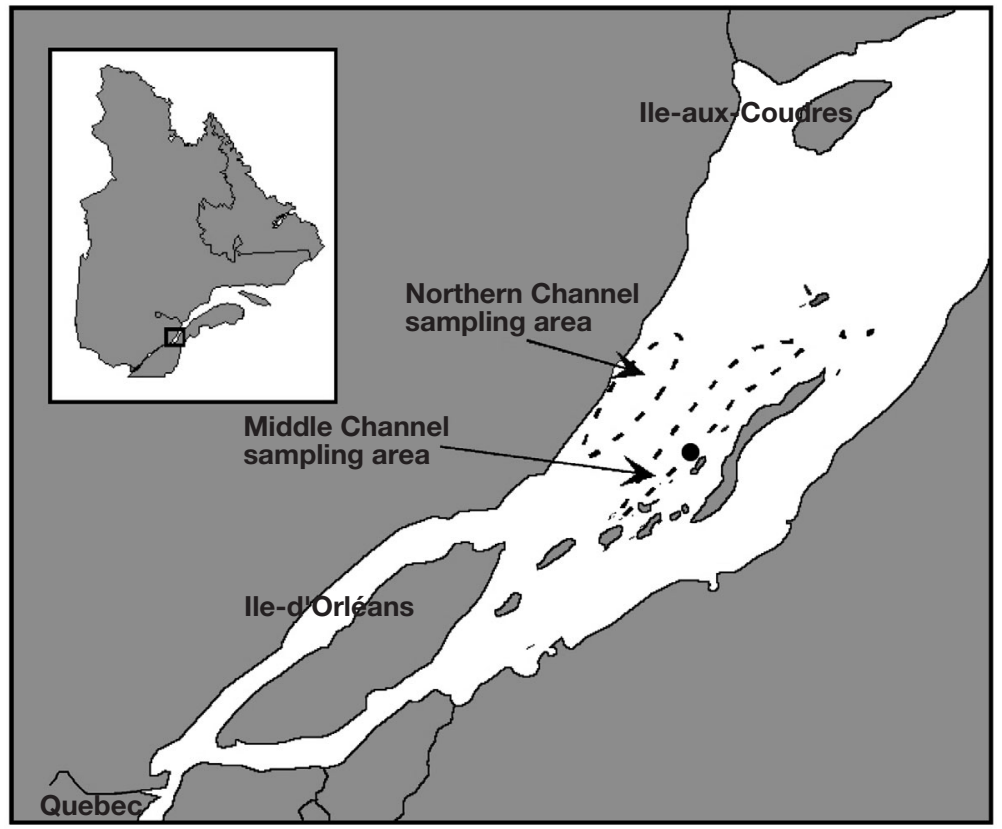

Fig. 1. St. Lawrence middle estuary sampling area, Quebec, Canada. The stations were sampled in 1996 (middle channel and northern channel) and 2001 (middle channel) (- station visited weekly in 2001). The insert shows the location of the middle estuary in eastern Canada hosts) and the mean intensity (average number of parasites in the infected hosts) of larvae collected in the 8 consecutive wk of sampling, with the exception of Week 6 of sampling, which was missed.

The effect of an infection is proportional to the intensity of infection (number of parasites present in an infected host) (Rosenthal 1967, Lemly 1982, Szalai \& Dick 1991, Brouder 1999). Moreover, the size of the parasite must also be considered, since a larger parasite occupies more space in the host and thus may have a greater effect (Rosenthal 1967). We thus developed a parasitism index to include the number of parasites found, as well as the dimensions (height, length, width) of each parasite. Because of the small size and mass of the parasite and the host, we preferred this method to the traditional parasite index (PI), which uses the mass of the parasite divided by the mass of the fish plus the mass of the parasite (Arme \& Owen 1967).

By considering the parasite as a flat cylinder, its biovolume $\left(V_{\mathrm{p}}\right)$ was estimated as:

$$
V_{\mathrm{p}}=\mathrm{p} / 4 \times \text { width } \times \text { height } \times \text { length }
$$

As the height of a flat cylinder is technically very difficult to measure, it was estimated by the regression: height $=[($ width +0.0918$) / 2.5088]\left(\mathrm{n}=30, \mathrm{R}^{2}=0.82\right)$. The biovolume of all parasites found in a larva was summed, and the total was corrected for the biovolume of the larva. By considering a larva as a cylinder, its biovolume $\left(V_{1}\right)$ was estimated as:

$$
V_{1}=\mathrm{p} / 4 \times \text { width }^{2} \times \text { length }
$$

The infection index estimate (I) of each larva was calculated as:

$$
I=\left(V_{\mathrm{p}} / V_{1}\right) \times 100
$$

Finally, we tested for parasite-induced host mortality by calculating the variance/mean parasite abundance ratio (Anderson \& Gordon 1982). As discussed by these authors, a decline of this ratio $<1$ is frequently associated with an under-dispersion of the parasite (i.e. less aggregated distribution of the parasites in the population host due to the death of heavily infected hosts). We thus calculated this ratio following the appearance of Proteocephalus tetrastomus in the larval fish population. Any changes in the variance/mean ratio observed between successive weeks was tested for significance as follows: the $\log$ (variance/mean ratio) for Week $x$ was subtracted from the log (variance/mean ratio) for Week $y$. This was repeated 1000 times, and a $95 \%$ bootstrap percentile interval was calculated (Efron \& Tibshirani 1993). If the resulting confidence interval included 0 , then the observed change in the variance/mean ratio could have been due to random chance alone.

Otolith measurements: One of the most powerful tools to evaluate an impact on the growth of fish larvae at the individual level is the analysis of otolith micro- 
structure (Campana 1990, Secor \& Dean 1992, Sirois et al. 1998). By comparing the data from different groups of fish, we may evaluate and quantify the impact of a given environmental variable on growth. Analysing otolith microstructure also provides a means to detect size-selective mortality. Given that factors affecting the growth of fish larvae may have an important impact on the size distribution of a cohort (involving directional, stabilising, or disruptive selection), the surviving members of a cohort are generally not representative of the original population. It is thus important to have individual information to describe the characteristics of the survivors relative to the original cohort.

To examine the effect of parasitism on growth and size-selective mortality, the larvae of Week 2 (before the arrival of the parasite) and Week 5 (3 wk after the arrival of the parasite, see Table 1) were used for otolith analyses. Sagittal otoliths were removed and fixed on a microscope slide. They were analysed using an image analysis system (MetaView 4.0) connected to a Zeiss microscope (Axiovert 100) at 1000× magnification. For each otolith, the core radius, the otolith radius and the width of every increment were measured 3 times by the same reader.

Sirois et al. (1998) developed a back-calculation method for rainbow smelt larvae. This time-varying growth method (TVG), unlike the biological intercept method (Campana 1990), weighs the contribution of each increment considering the biases caused by variations of the somatic growth rate over time. It thus provides better estimates of previous length-at-age than the biological intercept method at the individual level. Standard lengths $\left(L_{t}\right)$ were back-calculated from increments widths $\left(W_{t}\right)$ as:

$$
L_{t}=\underset{i=1}{L_{0}}+\sum\left[W_{t}+R\left(W_{t}-W\right)\right]\left(L_{\mathrm{c}}-L_{0}\right)\left(O_{\mathrm{c}}-O_{0}\right)^{-1}
$$

where $L_{0}$ is fish length at hatching, $L_{\mathrm{C}}$ is fish length at capture, $O_{0}$ is otolith radius at hatching, $O_{\mathrm{c}}$ is otolith radius at capture, $W_{t}$ is increment width at Age $t, W$ is mean increment width at a specific developmental stage (stage: 0 to $7 \mathrm{~d}, 8$ to $25 \mathrm{~d}, 26$ to $90 \mathrm{~d}$ ), and $R$ is the growth effect factor.

The core radius was used for the otolith radius at hatching $\left(O_{0}\right)$. Hatching length $\left(L_{0}\right)$ and the growth effect $(R)$ were estimated as $5.81 \mathrm{~mm}$ and 0.6, respectively, for wild-caught rainbow smelt larvae (Sirois et al. 1998).

Effect on vertical migration. 1996: To evaluate the impact of parasitism on the dispersion of smelt larvae, we examined differences in vertical distribution between infected and uninfected larvae. We first analysed archived samples obtained in July 1996 by Sirois \& Dodson (2000a). They collected rainbow smelt larvae in the middle (22 to 24 July) and northern channel (29 to 31 July) of the ETM (Fig. 1). During 4 sessions of
$12 \mathrm{~h}$ each (1 sampling every $1.5 \mathrm{~h}$ ), the water column was sampled by tracking the 0 to 2 psu salinity stratum as measured in surface waters. On each occasion, the surface ( 0 to $5 \mathrm{~m}$ ) and bottom (12 to $20 \mathrm{~m}$ ) layers were sampled using a Tucker trawl $(1.09 \times 1.19 \mathrm{~m})$ equipped with an opening-closing system and a $0.5 \mathrm{~m}$ standard plankton net (500 $\mu \mathrm{m}$ mesh). Each tow lasted approximately $15 \mathrm{~min}$, and the collected samples were preserved in $95 \%$ ethanol. A complete description of the methods is provided by Sirois \& Dodson (2000a).

2001: To complement the results obtained in 1996, we undertook additional sampling in the summer of 2001. On 11 July, we sampled the water column of the middle channel (Fig. 1) following the 0 to 2 psu salinity stratum as measured in surface waters during 12 consecutive hours. In 2001, 3 depths were sampled rather than 2 as in 1996. The surface ( 0 to $5 \mathrm{~m}$ ), middle (6 to $12 \mathrm{~m}$ ) and bottom (12 to $20 \mathrm{~m}$ ) layers were sampled using a Tucker trawl $(1.09 \times 1.19 \mathrm{~m})$ equipped with an opening-closing system and a $0.5 \mathrm{~m}$ standard plankton net $(500 \mu \mathrm{m}$ mesh). Each tow lasted approximately $15 \mathrm{~min}$, and the collected samples were preserved in $95 \%$ ethanol.

In the laboratory, larvae from 1996 and 2001 were analysed in the same way. When possible, 15 to 25 larvae were randomly selected, and their lengths and widths were measured using a camera connected to an image analysis system. Each larva was then dissected under a microscope, and the parasites observed in the digestive tract were counted and measured (length, width, height) using an ocular micrometer. A total of 583 larvae (1996 samples) and 201 larvae (2001 samples) were analysed.

Computations and statistical analyses. Otolith analyses: The presence of size-selective mortality was verified by comparing the growth rates of 2 groups of fish, the reference and survivor group, during a specific interval (Healey 1982, Meekan \& Fortier 1996). The reference population was considered to be the larvae collected in Week 2 (before the appearance of the parasite), as representative of the population at the initiation of parasitism. For the survivor group, we chose larvae from Week 5. At this time, the population had been exposed to the parasite for approximately $3 \mathrm{wk}$, and the parasitic infection rate had more than doubled between Weeks 4 and 5, increasing to a prevalence of $74 \%$ in Week 5. Subsequently, the parasitic infection rate levelled out at approximately $76 \%$.

All length back-calculations were done on natural log-transformed larval length and otolith radius. Larvae analysed were divided into 4 groups: the reference population (collected before arrival of the parasite) and the survivor population, which was further divided into 3 groups: uninfected $(I=0)$, weakly infected $(0<I<$ $0.17)$ and heavily infected $(I \geq 0.17)$. The parasitism index of 0.17 was the median value of all infected lar- 
vae (with the exclusion of 1 larva, which had a parasitism index twice the value of the second most parasitised fish).

Comparison of growth trajectories was carried out on the log-transformed back-calculated lengths using a repeated-measures ANOVA model as fitted in the MIXED procedure (SAS 2002). The data were split into 2 groups: pre-infection (Age 0 to $45 \mathrm{~d}$ ) and post-infection (Age 45 to $70 \mathrm{~d}$ ). Day 45 was chosen to divide the growth trajectories, as this was the approximate age at which the reference population was sampled. Thus, growth trajectories were available for both the reference and survivor populations. After Day 45, growth trajectories were available only for the survivor population. For the pre-infection group, the model included the following factors: population (survivor or reference), parasitic group (uninfected survivors, weakly infected survivors, or heavily infected survivors), age (d) of the larvae and their interactions. The post-infection model included parasitic group (for the survivors only), age of fish and their interactions. In both models, a first-order ante-dependence error structure (Kenward 1987) was used to model the within-subject covariance structure, while subjects were assumed to be independent. Tests for trends in the differences between growth trajectories were carried out using a fourth-order polynomial and the interaction of these terms with population (where appropriate) and parasitic group. In general, the differences between trajectories did not follow a simple linear or quadratic trend, and, for this reason, results are presented graphically. Differences between trajectories were backtransformed using the following formula:

$$
\text { Percent difference }=100 \times\left(\mathrm{e}^{(\text {estimated difference })}-1\right)
$$

along with a $95 \%$ confidence interval for the percent difference. These values are presented graphically as percent-difference trajectories. If the interval for a given age includes the value of 0 , then there is no significant difference between the 2 size trajectories at that age. If the interval does not include 0 , then there is a significant difference between the size trajectories at that point. It should be noted that comparisons at each day do not examine trends over time, and significant trends may exist even if, on an individual age basis, differences are not apparent.

Finally, differences in hatch date for the 2 populations and the 3 parasitic groups were examined using an ANOVA model with the fixed effect of population (reference or survivor) and with parasitic group (uninfected survivor, weakly infected survivor, heavily infected survivor). In addition, in the repeatedmeasures ANOVA, growth trajectories were adjusted for differing hatch dates. All tests were carried out at the $5 \%$ level of significance.
Size-selective mortality: To identify size-selective mortality, selection ratios were estimated for uninfected survivors, weakly infected survivors and heavily infected survivors. There are 2 ratios of interest; the first measures the proportional shift of the mean size of the surviving population relative to that of the reference population. The second ratio measures the proportional shift of the standard deviation of the surviving population relative to the reference population. Essentially, $\mathrm{SR}_{\mathrm{m}}$ is the mean size of survivors/mean size of individuals in the reference population and $\mathrm{SR}_{\mathrm{v}}$ is the standard deviation of the size of individuals in the survivor population/standard deviation of the size of individuals in the reference population. Selective pressures (as described by Brodie et al. 1995) indicate that positive directional selection will result in a positive proportional increase in $\mathrm{SR}_{\mathrm{m}}$ and a corresponding decrease in $\mathrm{SR}_{\mathrm{v}}$ (i.e. the mean increases in the surviving population while the standard deviation decreases). A corresponding proportional decrease in $\mathrm{SR}_{\mathrm{m}}$ occurs under negative directional selection, along with a proportional decrease in $\mathrm{SR}_{\mathrm{v}}$. An increase in $\mathrm{SR}_{\mathrm{v}}$ may be interpreted as disruptive selection. Both ratios are relevant in the discussion of selective pressures, as selection can act upon both the mean value of the selected characteristic and the variability of that characteristic in the population (Aubin-Horth et al. 2005, D. A. J. Ryan et al. unpubl. data).

Size selection was analysed by calculating $\mathrm{SR}_{\mathrm{m}}$ and $\mathrm{SR}_{\mathrm{v}}$ and comparing the infected and uninfected survivors with the reference population for 8 age classes: Days 1-6, 7-12, 13-18, 19-24, 25-30, 31-36, 37-42 and 43-45. We hypothesised that only the biggest and, hence, fastest growing larvae would be able to support the parasitic infection such that positive size selection should be observed regardless of the targeted age class of the infected survivor population. In contrast, positive size selection should not be as prominent in the uninfected survivor population. Presenting the data as a bivariate plot, populations undergoing positive directional selection will occur in the upper left-hand quadrant, negative directional selection will occur in the lower left-hand quadrant, positive disruptive selection will occur in the upper right-hand quadrant, and negative disruptive selection will occur in the lower right-hand quadrant. A population which has not undergone any selection will have a $\log$ (selection ratio) for both the mean and standard deviation that is not significantly different from 0 . On the bivariate plot, the estimated ratios will fall in the region around 0.

The empirical distribution of the selection ratios was calculated under the hypothesis of no selection using a randomisation procedure (Chernik 1999). Observations from the survivor and reference populations were randomly subsampled, and the corresponding selec- 
tion ratios were calculated. This randomisation routine was repeated 1000 times to create the randomisation distribution of the selection ratios under the null hypothesis that there was no selection. A 95\% percentile envelope for the empirical density was created using a bivariate kernel density estimator (SAS 2000). If the observed selection ratio fell outside this envelope, the age group was identified as undergoing significant selection. This was repeated for each age group. Selection ratios for each age group were then presented in a bivariate plot.

Vertical distribution analyses: Given that the sampling procedures of 1996 and 2001 were planned to cover an entire tidal cycle, it is possible to compare the distribution of the infected and uninfected larvae during a flooding and an ebbing tide. To achieve this, 2 methods were used. First, ANOVA was utilised to compare the prevalence and the parasitism index of the 1996 larvae found in the bottom (12 to $20 \mathrm{~m}$ ) and the surface layer ( 0 to $5 \mathrm{~m}$ ). In 2001, short-term variations in the vertical distribution of infected and uninfected larvae were documented by studying the fluctuations in the depth of the centre of mass of the distribution, $Z_{\mathrm{cm}}$ (Fortier \& Leggett 1983):

$$
Z_{\mathrm{cm}}=\sum_{i=1}^{3} p_{i} Z_{i}
$$

where $p_{i}$ is the proportion of larvae in the ith depth interval and $Z_{i}$ is average depth of the ith stratum.

\section{RESULTS}

\section{Parasitic infection and effect on growth}

Weekly sampling in 2001 revealed that Proteocephalus tetrastomus appeared in the St. Lawrence middle estuary between 18 June and 25 June. The infection began slowly, but rapidly increased to a maximum prevalence of $76 \%$ (Table 1). The parasitism index, which accounts for the relative volume of the parasite infection in the host Osmerus mordax, increased significantly each week from 0.008 to 0.61 later in the summer (Table 1). As explained earlier, the parasitism index was calculated as the sum of the biovolume of all parasites found in an individual larva divided by the biovolume of the larva. Given that the mean intensity remained stable from Week 5 to 8, the constant augmentation of the index in the summer was due to an augmentation of the parasite length/larva length ratio. The growth of smelt larvae was linear, whereas that of the parasite was exponential (Fig. 2). A change in the variance/mean abundance ratio was observed between Weeks 5 and 7. However, this difference was
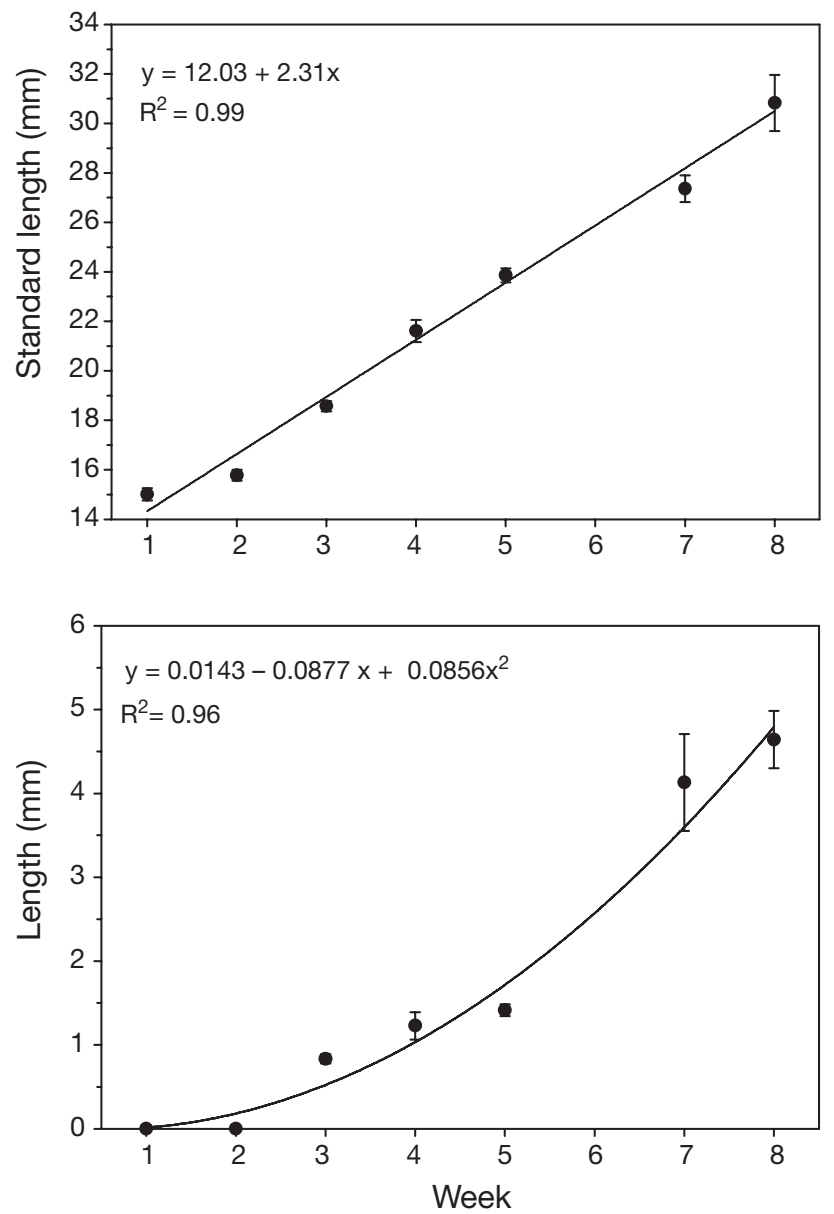

Fig. 2. Mean lengths of Osmerus mordax larvae (upper panel) and parasites (Proteocephalus tetrastomus, lower panel) during weekly sampling in 2001 (vertical bars: SE) 
not significant (the $95 \%$ bootstrap confidence interval included 0) and could have been due to chance alone. Coupled with the fact that the prevalence remained stable (Fig. 3), we conclude that the infection rate probably remained stable over the Weeks 5 to 8 .

\section{Growth trajectories: pre-infection (Age 0 to 45 )}

Mean back-calculated growth trajectories were determined for the period of growth prior to appearance of the parasite (Days 0 to 45) for all 4 groups: the reference population (sampled at Week 2) and the 3 survivor groups (sampled at Week 5): uninfected survivors, weakly infected survivors and heavily infected survivors. In all cases, significant growth was observed $(p<0.0001$, Fig. 4). Significant interactions in the shape of the growth trajectories were observed both between populations ( $\mathrm{p}<0.0001)$ and among groups within the survivor population ( $p=0.0029)$. Closer examination of the differences between populations using regression curves suggested complex interactions with significant second- to fourth-order polynomial terms ( $p=0.0013,0.0005$ and $<0.0001$, respectively). Differences in the growth trajectories between the 3 survivor groups and the reference population were described by a quadratic polynomial ( $p<0.0001)$. For this reason, differences were examined graphically (Fig. 5). The back-calculated size of uninfected survivors did not differ from the size of individuals in the reference population at any time during the $45 \mathrm{~d}$ preinfection period. The absence of size selectivity among uninfected survivors serves to demonstrate that net avoidance in this highly turbid and turbulent environ-

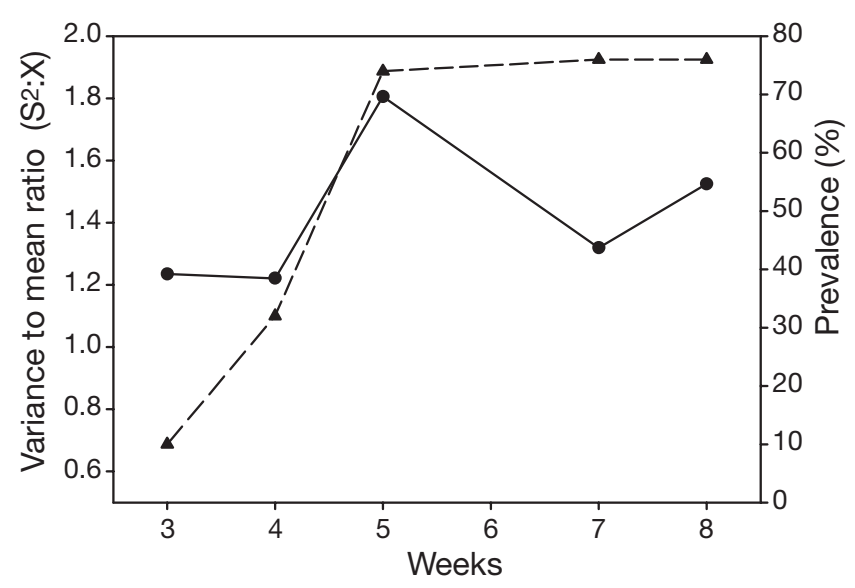

Fig. 3. Proteocephalus tetrastomus, Osmerus mordax. Changes in the dispersion of the parasite in rainbow smelt larvae with time (solid line: variance to mean ratios; dashed line: prevalence of the parasite)

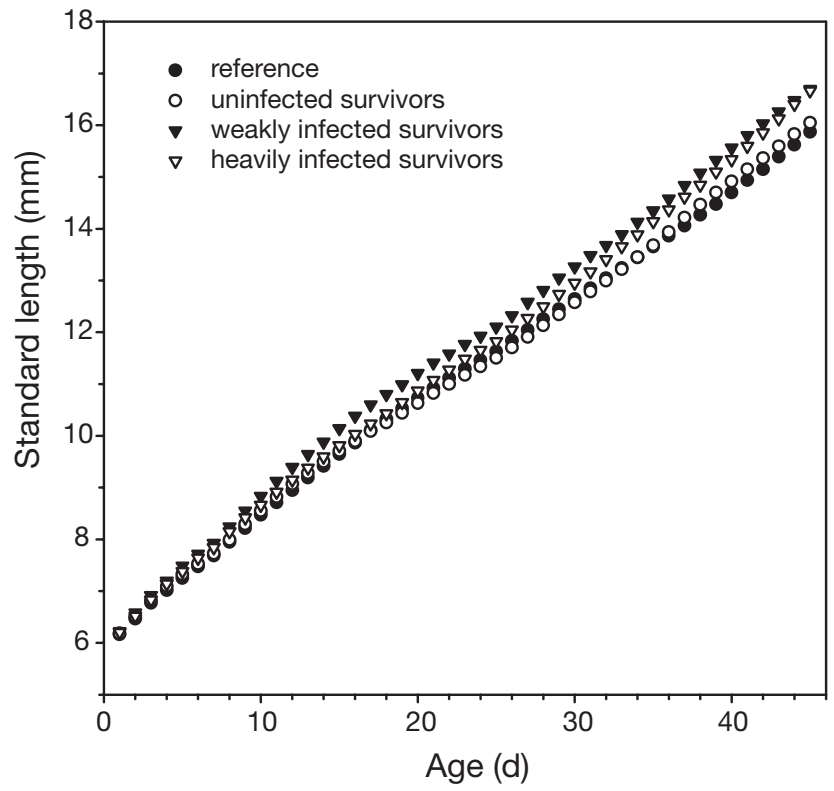

Fig. 4. Proteocephalus tetrastomus, Osmerus mordax. Mean back-calculated growth trajectories determined for the period of growth prior to appearance of the parasite (Days 0 to 45 ) for 4 groups of fish: the reference population (sampled at Week 2) and the 3 survivor groups (sampled at Week 5): uninfected, weakly, and heavily infected survivors

ment did not influence our interpretations of sizeselective mortality. If nets were avoided by faster growing larvae, we would have expected uninfected survivors to have exhibited a size disadvantage relative to the reference population at some point during the $45 \mathrm{~d}$ pre-infection period; this was not the case. In contrast to the uninfected survivors, the weakly infected survivors exhibited an early size advantage (a $1 \%$ size advantage at Day 1, which increased to approximately $5 \%$ by Day 12). At this point, the weakly infected survivors appeared to maintain an approximately constant $5 \%$ size advantage until Day 45. The heavily infected survivors exhibited an early $2 \%$ size advantage, but this slowly degraded only to reappear at Day 20 and become significant at Day 38.

Analysis of the hatch date data indicated that there were no significant differences in hatch date between populations $(p=0.08)$, or among parasitic groups within the survivor group $(p=0.49)$. Furthermore, there was evidence that the size of the individuals was related to the hatch date $(\mathrm{p}<0.0001)$, but there was no evidence of an interaction between hatch date and population $(\mathrm{p}=0.74)$, or between hatch date and parasitic group within the survivor population $(p=0.20)$. Thus, differences in the growth trajectories did not appear to be related to differences in hatch date. 
Growth trajectories: post-infection (Age 45 to 70)

A significant interaction between the survivor group and the fish age was found ( $p<0.0001$, Fig. 6). Closer inspection of the interaction suggested differences

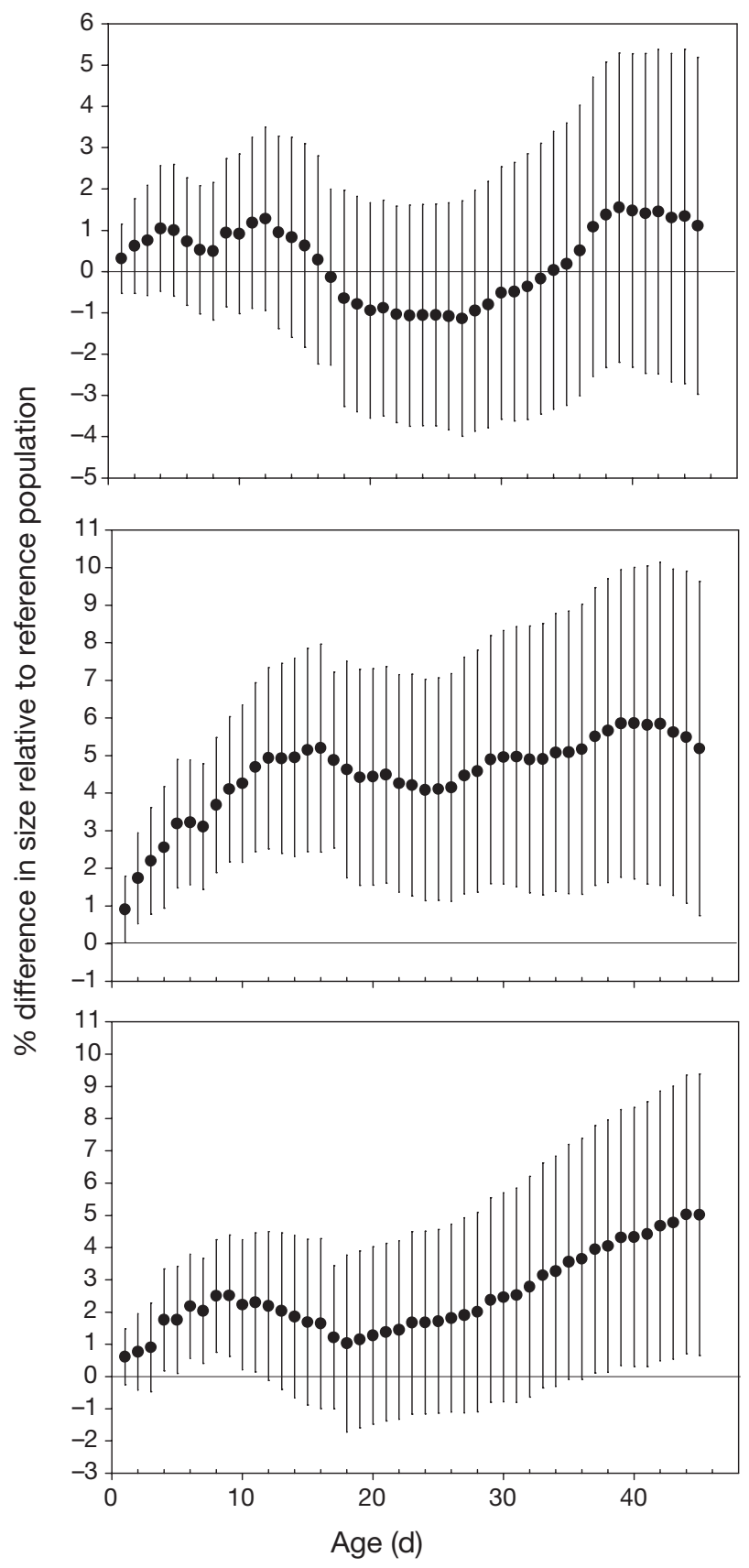

Fig. 5. Proteocephalus tetrastomus, Osmerus mordax. Percentage difference in size of the 3 survivor groups relative to the reference population over the first $45 \mathrm{~d}$ of life: the uninfected survivors (upper panel), the weakly infected survivors (middle panel) and the heavily infected survivors (lower panel) (vertical intervals: 95\% daily confidence interval for the percentage difference) between the growth trajectories of different parasitic groups were best described by a cubic polynomial over time, with significant interactions occurring between the first 3 terms of the polynomial and the age of the fish ( $p<0.0001$ in all cases). The weakly infected survivors initially exhibited an approximate $5 \%$ size advantage over the uninfected survivors at Day 46, which remained approximately constant until about Day 56. At this point the size advantage began to increase until Day 63, at which point a significant $6 \%$ size advantage was observed (Fig. 7). In contrast, the heavily infected survivors, while initially exhibiting a $5 \%$ size advantage, began losing that advantage at about Day 55, and continued to lose it until the end of the observation period, when their body sizes were approximately equal to those of uninfected survivors (Figs. 6 \& 7).

Including hatch date in the repeated-measures analysis for survivors suggested that, although there did appear to be significant differences in sizes of the fish between the parasitic groups ( $p<0.0001)$, the observed differences between the growth trajectories remained ( $p<0.0001)$. Thus, differences in the growth trajectories could not be accounted for by differences in hatch date.

\section{Size-selective mortality}

The selection ratios for the uninfected survivors were non-significant at the $5 \%$ level for all age groups except Group 2 (Fig. 8). In contrast, the selection ratios

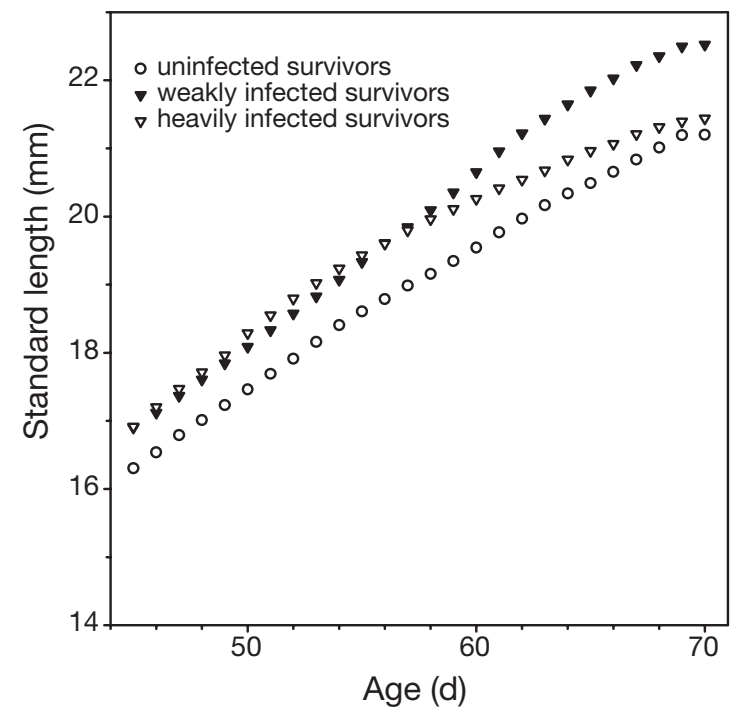

Fig. 6. Proteocephalus tetrastomus, Osmerus mordax. Mean back-calculated growth trajectories for the period of growth after the appearance of the parasite (Days 45 to 70 ) for the 3 survivor groups (sampled at Week 5): uninfected, weakly, and heavily infected survivors 


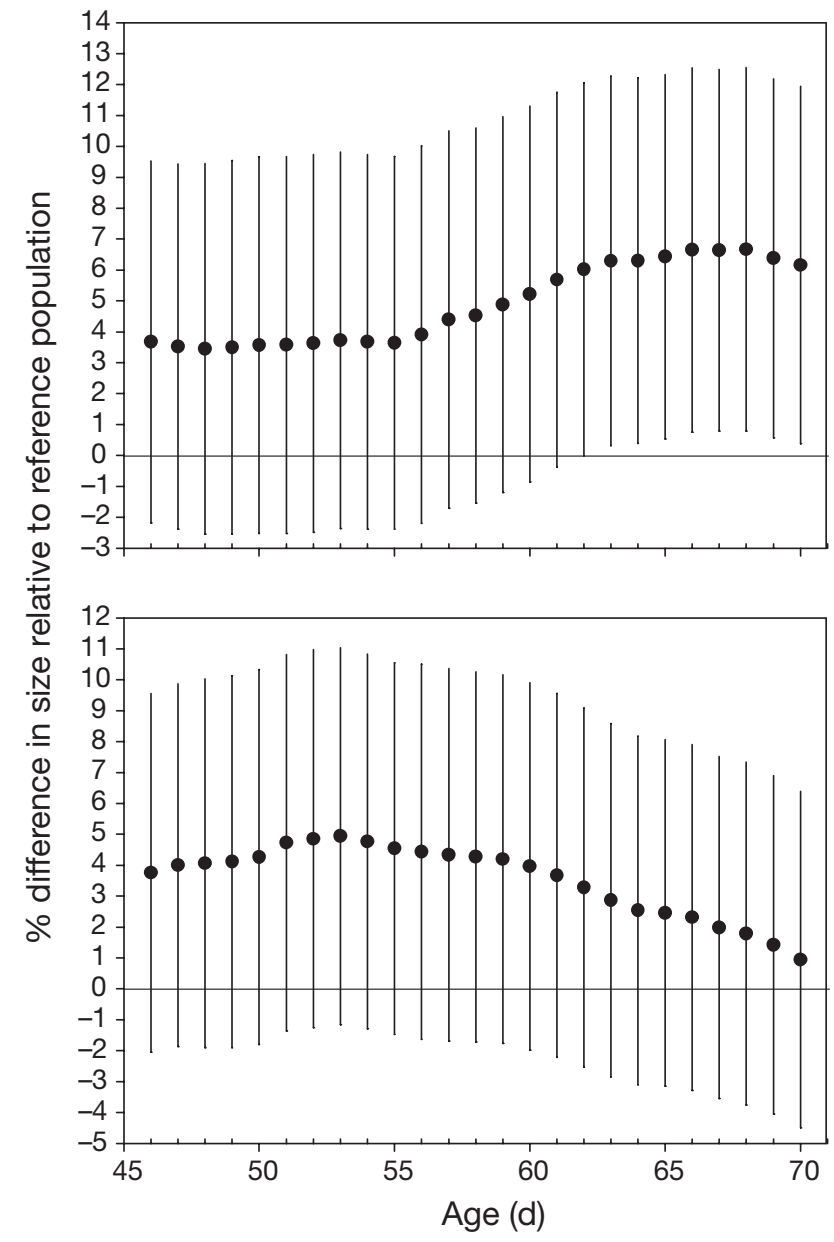

Fig. 7. Proteocephalus tetrastomus, Osmerus mordax. Percentage difference in growth trajectories between the weakly infected and the uninfected survivors (upper panel) and the heavily infected and the uninfected survivors (lower panel) (filled circles: mean percentage difference; vertical bars: $95 \%$ confidence intervals for the percentage difference)

at all ages were significant for all age groups of the weakly infected survivors. Significant positive selection was observed at each age group (most being significant at the $1 \%$ level, and some significant at the $5 \%$ level) (Fig. 8). A different trend was observed for the heavily infected survivors. At an early age, positive selection was evident at the $1 \%$ level, but was nonsignificant for Age Groups 2 through 5. The remaining 3 age groups demonstrated significant (at the 1\% level) size selection. In general, being bigger was definitely better for surviving parasitic infection.

\section{Effect on vertical migration}

Larvae from the 1996 sample were first analysed for the prevalence of parasitism. Comparison between lar-
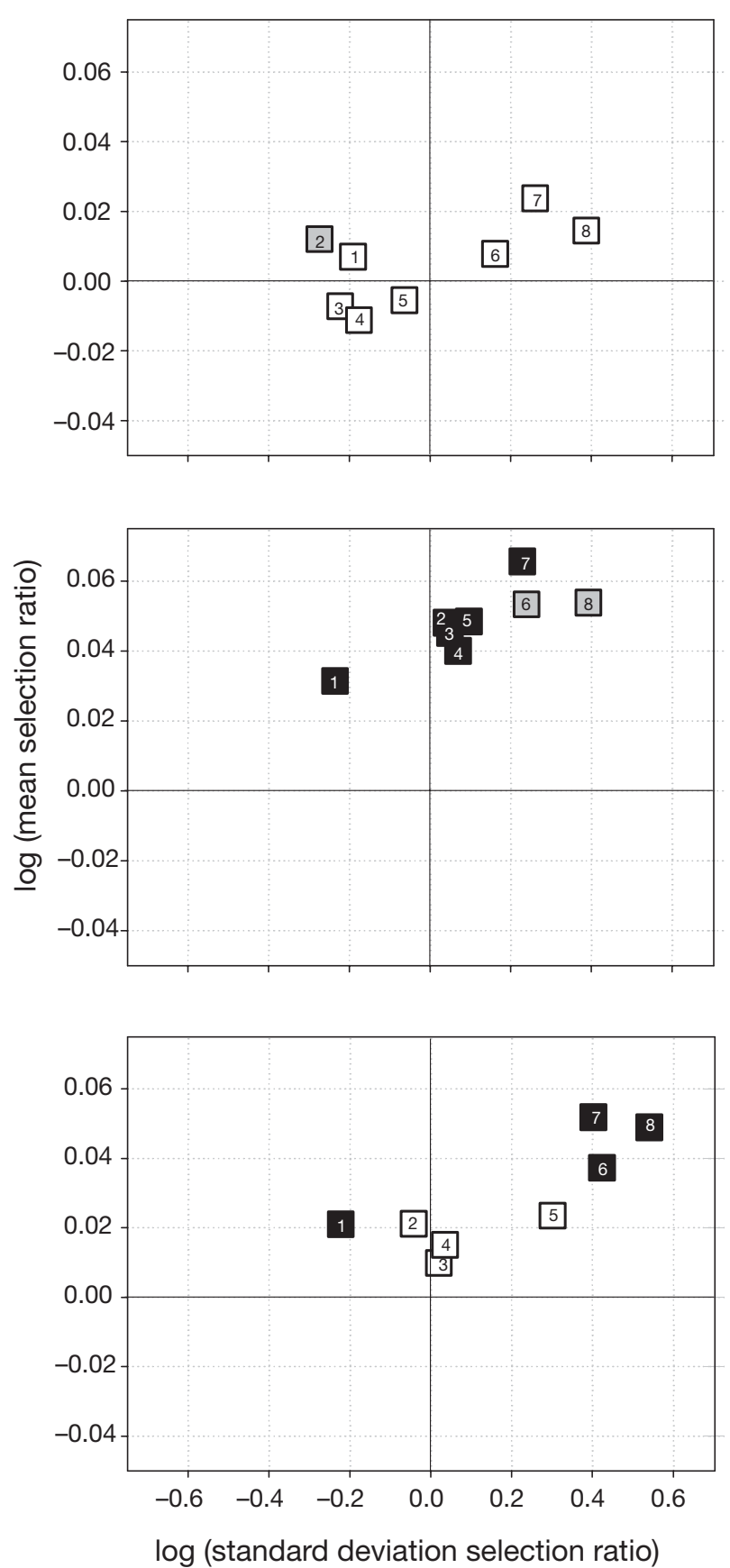

Fig. 8. Proteocephalus tetrastomus, Osmerus mordax. Bivariate plots of the $\log ($ selection ratios). The vertical axis represents the logarithm of the mean selection ratio, while the horizontal axis represents the logarithm of the standard deviation of the selection ratio. The bivariate $\log$ (selection ratios) are represented by white squares if not significantly different from 0 , grey squares if significantly different from 0 at the $5 \%$ level and black squares if significantly different from 0 at the $1 \%$ level. The symbols are numbered chronologically from 1 for the $\log$ (selection ratios) at Day 6, to 8 for the $\log$ (selection ratios) at Day 45. The upper panel displays the log(selection ratios) for the uninfected survivors, while the middle and lower panels display the $\log$ (selection ratios) for the weakly and heavily infected survivors, respectively 
Table 2. Proteocephalus tetrastomus, Osmerus mordax. Prevalence (Prev.) of parasites in rainbow smelt larvae collected in the surface and bottom layers of the estuarine turbidity maximum during ebbing and flooding tides in 1996

\begin{tabular}{|lccccccccc|}
\hline & \multicolumn{4}{c}{ Northern channel } & \multicolumn{4}{c|}{ Middle channel } \\
& $\mathrm{n}$ & $\begin{array}{c}\text { Prev. } \\
(\%)\end{array}$ & SD & $\mathrm{p}$ & $\mathrm{n}$ & $\begin{array}{c}\text { Prev. } \\
(\%)\end{array}$ & $\mathrm{SD}$ & $\mathrm{p}$ \\
& & & & & & & \\
\hline Ebbing & & & & & & & & \\
Surface & 67 & 43.3 & 49.9 & & 67 & 31.3 & 46.7 & \\
Bottom & 67 & 34.3 & 47.8 & & 56 & 33.9 & 47.8 & \\
& & & & 0.29 & & & & 0.76 \\
Flooding & & & & & & & \\
Surface & 69 & 42 & 49.7 & & 105 & 40 & 49.2 & \\
Bottom & 72 & 44.4 & 50 & & 90 & 34.4 & 47.8 & \\
& & & & 0.77 & & & & 0.43 \\
\hline
\end{tabular}

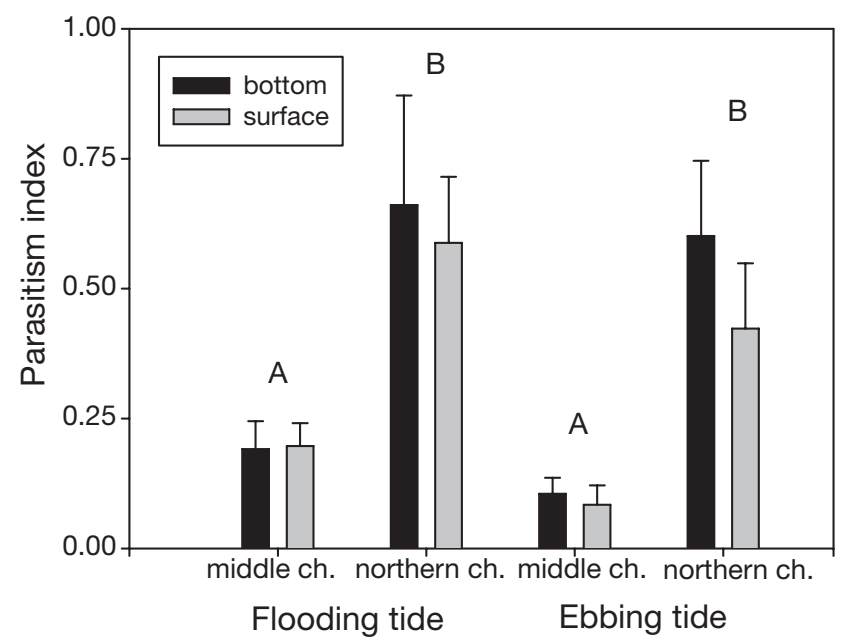

Fig. 9. Proteocephalus tetrastomus, Osmerus mordax. Mean parasitism index of the larvae collected in the surface and bottom layers during the flooding and the ebbing tides in the northern and middle channels of the St. Lawrence estuarine turbidity maximum in July 1996 (vertical bars: SE; different letters above bars: significant differences among parasitism indices)

vae collected in bottom and surface layers indicated no significant difference in the proportion of infected larvae, in either the northern channel or the middle channel (Table 2). We then analysed for differences in the mean parasitism index calculated for larvae found in the bottom and surface during the 2 different tide states and the 2 different channels (Fig. 9). Again, no significant differences were found, suggesting that Proteocephalus tetrastomus did not influence the vertical distribution of larvae. However, there was a significant difference in the parasitism index between the 2 channels. This difference is probably attributable to the $7 \mathrm{~d}$ separating the 2 sampling periods. As illustrated in Table 1, a marked increase was observed in the parasitism index during this time period.

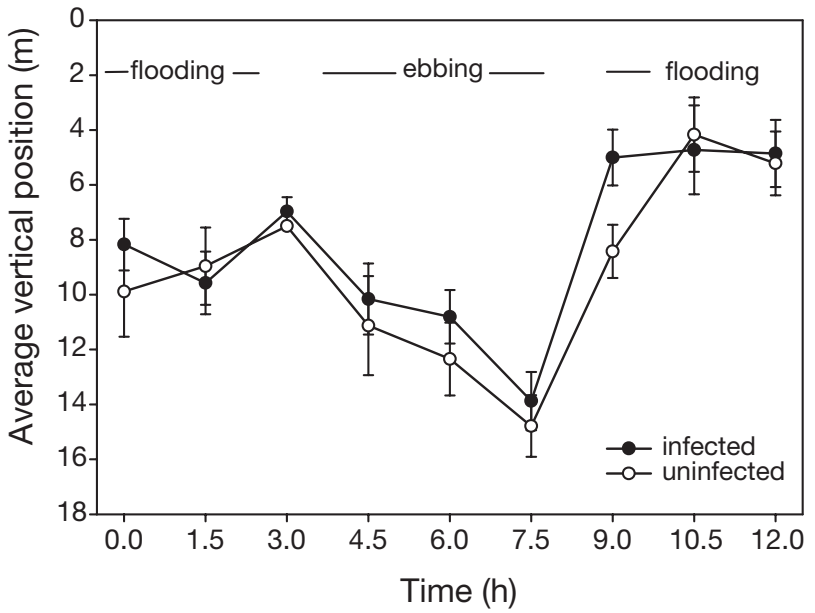

Fig. 10. Proteocephalus tetrastomus, Osmerus mordax. Average vertical position $\left(Z_{\mathrm{cm}}\right)$ of the infected and uninfected smelt larvae collected in the estuarine turbidity maximum in July 2001 (vertical bars: SE)

Analysis of the centre of mass $\left(Z_{\mathrm{cm}}\right)$ of the larvae collected in 2001 in the middle channel of the ETM showed the general pattern expected of the vertical migration of rainbow smelt larvae, with most of the larvae found at the surface during the flooding tide (Fig. 10). However, no significant difference in the general pattern of distribution of the infected and uninfected larvae was found ( $p>0.05$ at each time except at $9.0 \mathrm{~h}$ ).

\section{DISCUSSION}

\section{Impact on growth and mortality}

The comparison between size-at-age observed prior to parasitic infection by Proteocephalus tetrastomus (Days 1 to 45) and that back-calculated to the same time period from Osmerus mordax larvae surviving to Week 5 showed that the survivors tended to either have consistently higher growth rates (weakly infected larvae) than larvae composing the reference population, or, at the very least, higher growth rates than the reference population during the 2 to $3 \mathrm{wk}$ period prior to infestation (heavily infected larvae). After the initial period of infection (Days 46 to 70), we still observed a greater size-at-age of the weakly infected larvae compared to the uninfected ones. However, the heavily infected larvae experienced a decline in growth at the end of the observation period. This dramatic decline in growth is probably related to the energetic demands of a heavy parasitic infection, and the size advantage required to survive the parasitic infection thus appears to be eliminated as growth rate declines over time due to heavy parasitic infection. 
These observations suggest that larvae with an average or less than average growth rate do not tolerate a parasitic infection to the same extent as fish with a higher than average growth rate and will suffer increased mortality. Indeed, this was also evident in the analysis of size-selective mortality. Positive selection ratios occurred in all age classes of the weakly infected larvae, reflecting the fact that the faster growing fish were larger at the time of infection, allowing them to survive. With the heavily infected fish, there was no evidence of selection on the early fish, as they exhibited the same size-at-age as the uninfected fish, but achieved rapid growth prior to infection, possibly allowing them the size advantage required to survive at least for a few weeks.

The benefits of faster growth in larval smelt may be compromised by the distribution of infective cestode larvae among copepod populations. Susceptibility to infection by larval cestodes is known to vary among developmental stages in copepods (Marcogliese 1995). Among proteocephalid cestodes, older copepodites and adults possess higher levels of infection than younger copepodite stages and overall densities of infected later stages are higher than earlier infected stages (Hanzelová et al. 1989, Rusinek et al. 1996). Fish are known to be gape-limited predators, and larger fish and larvae will consume larger prey items (i.e. older copepodites and adult copepods) and more of them than smaller specimens. Thus, the largest smelt larvae may be at a higher risk of infection than smaller forms. There thus may be a trade-off between the higher probability of survival and greater risk of infection at large size, resulting in the degrading size advantage that was observed in heavily infected survivors. This trade-off would be most apparent during years of high prevalence of Proteocephalus tetrastomus.

\section{Impact on vertical migration}

Smelt larvae need to actively migrate to the surface layer of the water column to feed and to achieve retention within the ETM (Laprise \& Dodson 1989, Sirois \& Dodson 2000a). This behaviour demands surplus energy, and weak larvae are thus expected to be advected downstream of the ETM. However, we did not detect any direct impact of parasitism on the vertical distribution of smelt larvae. Furthermore, Dauvin \& Dodson (1990) did not find any differences in the intensity of parasitism between larvae found at the upstream versus the downstream end of the ETM, possibly indicating that larvae found downstream are not parasitised larvae lost from the upstream nursery area. We propose that these observations may be related to the energy allocation hypothesis of Wieser
(1991) who predicted that, in the presence of food deprivation, the locomotor activity and searching behaviour of fish larvae should initially increase, despite the energetic costs. Although speculative, parasitised smelt larvae must continue to migrate vertically even if the energy expended is not available for growth, as vertical migration on the flooding tide is associated with feeding (Sirois \& Dodson 2000a). The size-selective mortality of smelt larvae, thus, cannot be ascribed to downstream advection and loss from the nursery area.

In the absence of any evidence involving impairment of the vertical migration of parasitised larvae, increased size-selective mortality among parasitised larvae is most likely associated with either starvation or predation. Sirois \& Dodson (2000a) have already shown that parasitised larvae from the St. Lawrence estuary had significantly less food in their guts than uninfected ones, possibly leading to starvation. Although piscivorous predation is largely absent from this region, invertebrate predation may be significant. Although the common invertebrate marine predators such as chaetognaths, cnidarians and ctenophores are absent from the ETM brackish water, many other potential predators are found in high densities, for example, the sand shrimp Crangon septemspinosa, a documented predator of fish larvae (Bertram \& Leggett 1994, Witting \& Able 1995, Asahida et al. 1997). Investigations of predation must be carried out before we can conclude that predation contributes to the sizeselective mortality of rainbow smelt larvae documented here.

\section{Impact of parasitism on smelt recruitment}

The impact of size-selective mortality will not affect variability in recruitment unless the factors governing size-based processes vary themselves on an interannual basis (Rice et al. 1997). The prevalence of the infection by Proteocephalus tetrastomus documented in different studies spanning $20 \mathrm{yr}$ is highly variable (Table 3). We have shown that parasitism significantly influences size-selective mortality and thus conclude that parasitism plays a significant role in regulating recruitment of rainbow smelt in the St. Lawrence estuary. However, the nature of this regulation must surely be complex. We know that the emergence and the development rate of proteocephalid cestodes are controlled largely by temperature (Scholz 1999). A cold year may delay the appearance of the parasite in the system, allowing smelt larvae to grow larger before being infected. Temperature also controls primary production and thus zooplankton populations, such as Eurytemora affinis, which probably acts as an inter- 
Table 3. Proteocephalus tetrastomus, Osmerus mordax. Interannual variation of the prevalence of parasitism in the guts of rainbow smelt larvae collected at the end of July in the St. Lawrence estuary. All studies were conducted between Île d'Orléans and Île aux Coudres, with the exception of the 1979 study, which was conducted downstream of l̂le aux Coudres

\begin{tabular}{|ccl|}
\hline Year & $\begin{array}{c}\text { Prevalence } \\
(\%)\end{array}$ & \multicolumn{1}{c|}{ Source } \\
\hline 1979 & 57 & Courtois \& Dodson (1986) \\
1985 & 96 & Dauvin \& Dodson (1990) \\
1996 & 38 & Sirois \& Dodson (2000a,b) \\
2000 & 43 & Present study, authors' unpubl. data \\
2001 & 76 & Present study \\
\hline
\end{tabular}

mediate host for the parasite (given that this species is the only copepod found in high densities in the ETM). A delay in the arrival of this copepod may negatively affect larval survival as proposed by the matchmismatch hypothesis (Cushing 1975), but may also positively affect smelt larvae by delaying parasite recruitment. Although long time series relating the prevalence of parasitism to adult population abundance are presently lacking, we provide indirect support for the hypothesis that parasitism of the early life-history stages is a significant source of recruitment variability in this species.

Acknowledgements. We particularly thank Pascal Sirois for precious data, samples and guidance. We also thank Julie Hébert, Frédéric Lecomte, Andrée Gendron, Jean-Yves Anctil and Pierre Bérubé for field assistance and laboratory work. Special thanks to Faune et Parc Quebec, the Aquarium du Quebec and the St. Lawrence Centre (Environment Canada) for collaboration. Funding of this project was provided to J.J.D. by NSERC of Canada. This study is a contribution to the program Quebec-Ocean.

\section{LITERATURE CITED}

Anderson RM, Gordon DM (1982) Processes influencing the distribution of parasite numbers within host populations with special emphasis on parasite-induced host mortalities. Parasitology 85:373-398

Arme C, Owen RW (1967) Infections of the three-spined stickleback, Gasterosteus aculeatus L., with the plerocercoid larvae of Schistocephalus solidus with special reference to pathological effects. Parasitology 57:301-304

Asahida T, Yamashita Y, Kobayashi T (1997) Identification of consumed stone flounder, Kareius bicoloratus, from the stomach contents of sand shrimp, Crangon affinis, using mitochondrial DNA analysis. J Exp Mar Biol Ecol 217: 153-163

Aubin-Horth N, Ryan DAJ, Good SP, Dodson JJ (2005) Balancing selection on size: effects on the incidence of an alternative reproductive tactic. Evol Ecol Res 7:1171-1182

Bailey KM, Houde ED (1989) Predation on eggs and larvae of marine fishes and the recruitment problem. Adv Mar Biol 25:1-67

Balbuena JA, Karlsbakk E, Kvenseth AM, Saksvik M,
Nylund A (2000) Growth and emigration of third-stage larvae of Hysterothylacium aduncum (Nematoda: Anisakidas) in larval herring Clupea harengus. J Parasitol 86: 1271-1275

Baldwin NL, Millemann RE, Knapp SE (1967) 'Salmon poisoning' disease. III. Effects of experimental Nanophyetus salmonicola infection on the fish host. J Parasitol 53: 556-564

Barber I, Hoare D, Krause J (2000) Effects of parasites on fish behaviour: a review and evolutionary perspective. Rev Fish Biol Fish 10:131-165

Baturo B (1978) Larval bucephalosis in artificially heated lakes of the Konin region, Poland. Acta Parasitol Pol 25: 307-321

Bean CW, Winfield IJ (1992) Influences of the tapeworm Ligula intestinalis (L.) on the spatial distributions of juvenile roach Rutilus rutilus (L.) and gudgeon Gobio gobio (L.) in Lough Neagh, Northern Ireland. Neth J Zool 42: 416-429

Bertram DF, Leggett WC (1994) Predation risk during the early life history periods of fishes: separating the effects of size and age. Mar Ecol Prog Ser 109:105-114

Brodie ED, Moore AJ, Janzen FJ (1995) Visualizing and quantifying natural selection. Trends Evol Ecol 10:313-318

Brouder MJ (1999) Relationship between length of roundtail chub and infection intensity of Asian fish tapeworm Bothriocephalus acheilognathi. J Aquat Anim Health 11: 302-304

Campana SE (1990) How reliable are growth back-calculations based on otoliths? Can J Fish Aquat Sci 47:2219-2227

Chernick MR (1999) Bootstrap methods. A practitioner's guide. John Wiley \& Sons, Toronto

Coleman FC (1993) Morphological and physiological consequences of parasites encysted in the bulbus arteriosus of an estuarine fish, the sheephead minnow, Cyprinodon variegatus. J Parasitol 79:247-254

Courtois R, Dodson JJ (1986) Régime alimentaire et principaux facteurs influençant l'alimentation des larves de capelan (Mallotus villosus), d'éperlan (Osmerus mordax) et de hareng (Clupea harengus) dans un estuaire partiellement mélangé. Can J Fish Aquat Sci 43: 968-979

Cushing DH (1975) Marine ecology and fisheries. University Press, Cambridge

D'Anglejan B, Smith EC (1973) Distribution, transportation and composition of suspended matter in the St. Lawrence estuary. Can J Earth Sci 10:1380-1396

Dauvin JC, Dodson JJ (1990) Relationship between feeding incidence and vertical and longitudinal distribution of rainbow smelt larvae (Osmerus mordax) in a turbid wellmixed estuary. Mar Ecol Prog Ser 60:1-12

Efron B, Tibshirani RJ (1993) An introduction to the bootstrap. Chapman \& Hall, London

Fortier L, Leggett WC (1983) Vertical migrations and transport of larval fish in a partially mixed estuary. Can J Fish Aquat Sci 40:1543-1555

Godin JG, Sproul CD (1988) Risk taking in parasitized sticklebacks under threat of predation: effects of energetic need and food availability. Can J Zool 66:2360-2367

Hanzelová V, Sysoev AV, Žitňan A (1989) Ecology of Proteocephalus neglectus La Rue, 1911 (Cestoda) in the stage of procercoid in Dobšiná dam (East Slovakia). Helminthologia 26:105-116

Healey MC (1982) Timing and relative intensity of size-selective mortality of juvenile chum salmon (Oncorhynchus keta) during early sea life. Can J Fish Aquat Sci 39: 952-957

Heath M, Nicoll N (1991) Infection of larval herring by 
helminth parasites in the North Sea and the effect on feeding incidence. Cont Shelf Res 11:1477-1489

Hjort J (1914) Fluctuations in the great fisheries of northern Europe reviewed in the light of biological research. Rapp P-V Reun Cons Int Explor Mer 20:1-128

Holmes JC, Zohar S (1990) Pathology and host behaviour. In: Barnard CJ, Behnke JM (eds) Parasitism and host behaviour. Taylor \& Francis, London, p 193-229

Karlsbakk E, Otterlei E, Hoie H, Nylund A (2001) Parasites of cultured cod Gadus morhua postlarvae fed natural zooplankton. Bull Eur Assoc Fish Pathol 21:63-70

Kenward MG (1987) A method for comparing profiles of repeated measurements. Appl Stat 36:296-308

Kranck (1979) Dynamics and distribution of suspended particulate matter in the St. Lawrence estuary. Nat Can (Que) 106:163-173

Laprise R, Dodson JJ (1989) Ontogeny and importance of tidal vertical migration in the retention of larval smelt Osmerus mordax in a well-mixed estuary. Mar Ecol Prog Ser 55: $101-111$

Lasker R (1978) The relation between oceanographic conditions and larval anchovy food in the California Current: identification of factors contributing to recruitment failure. Rapp P-V Reun Cons Int Explor Mer 173: 212-230

Lecomte F, Dodson JJ (2004) Role of early life-history constraints and resource polymorphism in the segregation of sympatric populations of an estuarine fish. Evol Ecol Res 6: 631-658

Lemly AD (1982) Effects of a larval parasite on the growth and survival of young bluegill. Proc Annu Conf Southeast Assoc Fish Wildl Agency 34:263-274

Lester RJG (1971) The influence of Schistocephalus plerocercoids on the respiration of Gasterosteus and a possible resulting effect on the behavior of the fish. Can J Zool 49: 361-366

LoBue CP, Bell MA (1993) Phenotypic manipulation by the cestode parasite Schistocephalus solidus of its intermediate host Gasterosteus aculeatus, the threespine stickleback. Am Nat 142:725-735

Marcogliese DJ (1995) The role of zooplankton in the transmission of helminth parasites to fish. Rev Fish Biol Fish 5: 336-371

Meekan MG, Fortier L (1996) Selection for fast growth during the larval life of Atlantic cod Gadus morhua on the Scotian Shelf. Mar Ecol Prog Ser 137:25-37

Milinski M (1985) Risk of predation of parasitized sticklebacks (Gasterosteus aculeatus) under competition for food. Behaviour 93:203-216

Miller TJ, Crowder LB, Rice JA, Marshall EA (1988) Larval size and recruitment mechanisms in fishes: toward a conceptual framework. Can J Fish Aquat Sci 45:1657-1670

Poulin R, FitzGerald GJ (1989) Risk of parasitism and microhabitat selection in juvenile sticklebacks. Can J Zool 67: $14-18$

Rice JA, Croder LB, Marschall EA (1997) Predation on juvenile fishes: dynamic interactions between size-structured predators. In: Chambers RC, Trippel EA (eds) Early life history and recruitment in fish populations. Chapman \&

Editorial responsibility: Otto Kinne (Editor-in-Chief), Oldendorf/Luhe, Germany
Hall, New York, p 333-356

Rosenthal H (1967) Parasites in larvae of the herring (Clupea harengus L.) fed with wild plankton. Mar Biol 1:10-15

Rusinek OT, Bakina MP, Nikolskii AV (1996) Natural infection of the calanoid crustacean Epischura baicalensis by procercoids of Proteocephalus sp. in Listvenichnyi Bay, Lake Baikal. J Helminthol 70:237-247

SAS (2000) SAS Online Doc, Version 8. SAS Institute, Cary, $\mathrm{NC}$

Scholz T (1999) Life cycles of species of Proteocephalus, parasites of fishes in the Paleartic region: a review. J Helminthol 73:1-19

Scholz T, Marcogliese DJ, Bourque JF, Škeříková A, Dodson JJ (2004) Occurrence of Proteocephalus tetrastomus (Rudolphi, 1810) (Cestoda: Proteocephalidea) in larval rainbow smelt (Osmerus mordax) in North America: identification of a potential pathogen confirmed. J Parasitol 90: 425-427

Secor DH, Dean JM (1992) Comparison of otolith-based backcalculation methods to determine individual growth histories of larval striped bass, Morone saxatilis. Can J Fish Aquat Sci 49:1439-1454

Sinclair M (1988) Marine populations. University of Washington Press, Seattle, WA

Sindermann CJ (1986) Effects of parasites on fish populations: practical considerations. Int J Parasitol 17:371-382

Sirois P, Dodson JJ (2000a) Influence of turbidity, food density and parasites on the ingestion and growth of larval rainbow smelt Osmerus mordax in an estuarine turbidity maximum. Mar Ecol Prog Ser 193:167-179

Sirois P, Dodson JJ (2000b) Critical periods and growthdependent survival of larvae of an estuarine fish, the rainbow smelt Osmerus mordax. Mar Ecol Prog Ser 203: $233-245$

Sirois P, Lecomte F, Dodson JJ (1998) An otolith-based backcalculation method to account for time-varying growth rate in rainbow smelt (Osmerus mordax) larvae. Can J Fish Aquat Sci 55:2662-2671

Smith HD, Margolis L (1970) Some effects of Eubothrium salvelini (Schrank, 1790) on sockeye salmon, Oncorhynchus nerka (Walbaum) in Babine Lake, British Columbia. J Parasitol 56:321-322

Szalai AJ, Dick TA (1991) Role of predation and parasitism in growth and mortality of yellow perch in Dauphin Lake, Manitoba. Trans Am Fish Soc 120:739-751

Vincent WF, Dodson JJ (1999) The St. Lawrence River, Canada-USA: the need for an ecosystem-level understanding of large rivers. Jpn J Limnol 60: 29-50

Wieser W (1991) Limitations of energy acquisition and energy use in small poikilotherms: evolutionary implications. Funct Ecol 5:234-240

Winkler G, Dodson JJ, Bertrand N, Thivierge D, Vincent WF (2003) Trophic coupling across the St. Lawrence River estuarine transition zone. Mar Ecol Prog Ser 251:59-73

Witting DA, Able KW (1995) Predation by sevenspine bay shrimp Crangon septemspinosa on winter flounder Pleuronectes americanus during settlement: Laboratory observations. Mar Ecol Prog Ser 123:23-31

Submitted: April 21, 2005; Accepted: November 5, 2005

Proofs received from author(s): April 21, 2006 